\title{
PENYAKIT JIWA DI KOMUNITAS
}

\author{
ArumPratiwi, Abi Muhlisin, Agus Sudaryanto dan Sahuri Teguh kurniawan \\ Jurusan Keperawatn - Fakultas Ilmu Kesehatan \\ Universitas Muhammadiyah Surakarta \\ J1. A. Yani Pabelan Kartasura Surakarta 57102; Email : arum_Pratiwi@ums.ac.id
}

\begin{abstract}
PAKOM activities purpose to help resolve the community problem about suffering from mental illnes. Patients recovering from a mental disorder burden in the family, another result was isolated by society because they considered dangerouse. PAKOM was conducted in a Nguter village of Sukoharjo district. These problems possibility can be solved with build up the community mental health center. The purpose of this activity is to create the community mental health center as a first home base and rehabilitation services the mental illness in a community. Base on the health center are expected the mentally ill patients able to socialize with the community, engaging in activities in the community, as a result the patient's quality of life better and impact to the decreasing recurrence rate level mental disorders in the community.
\end{abstract}

Key words ; Mental Disorders, Community Mental Health Services.

\section{PENDAHULUAN}

Kabupaten Sukoharjo yang terletak di Jawa Tengah kabupaten Sukoharjo memiliki sekitar 713 kasus psikosis dari 65706 penduduk pada tahun 2011 pada 12 kecamatan. Ada tiga kecamatan di Sukoharjo yang memiliki jumlah tertinggi dengan gangguan mental yaitu daerah Nguter memiliki 341 kasus dari 6463 orang, kecamatan Tawangsari memiliki 293 kasus gangguan mental dari 4488 penduduk, dan kecamatan Weru memiliki 203 kasus dari 5952 orang. (Dinas Kesehatan Kabupaten Sukoharjo, 2011).

Pasien pasca sembuh dari gangguan jiwa yang tidak produktif menjadi beban ketergantungan dalam keluarga, akibat lain adalah diisolir oleh masyarakat karena dianggap tidak berguna dan sering mengamuk yang menyebabkan tingkat kekambuhan tinggi. Apabila pasien kembali ke rumah sakit jiwa maka membutuhkan biaya yang sangat mahal diantaranya adalah membayar biaya rawat inap, pemeriksaan dokter, dan obat.

Angka kekambuhan yang tinggi salah satunya disebabkan persepsi, sikap dan perilaku masyarakat terhadap penyakit jiwa. Masyarakat cenderung berfikir bahwa orang yang menderita penyakit jiwa tidak bisa sembuh, tidak bisa bergaul dengan orang lain. Penelitian Pratiwi dan Nurlaily, 2010 menemukan bahwa keluarga yang mempunyai anggota keluarga gangguan jiwa cenderung mengisolasi pasien karena dianggap tidak berguna dan khawatir sewaktu-waktu bisa kambuh.

Persepsi masyarakat diatas dikarenakan kurangnya pengetahuan masyarakat tentang penyakit jiwa. 
Pengetahuan masyarakat yang kurang ini akibat dari masih kurangnya informasi yang harus diberikan oleh tenaga kesehatan kepada masyarakat mengenai penyakit jiwa. Beberapa permasalahan yang mendukung kondisi ini adalah letak Puskesmas (Pusat Kesehatan Masyarakat) yang jauh dari pedesaan tempat tinggal masyarakat yang mempunyai anggota keluarga dengan gangguan jiwa: 1) Letak puskesmas yang lebih dari 20 kilometer ini menyebabkan pasien dan keluarga kesulitan untuk mendapatkan akses langsung fasilitas kesehatan terutama yang bersifat kegawat daruratan. 2) belum adanya posyandu kesehatan jiwa dan fasiliatanya di pedesaan. Posyandu yang ada selama ini hanya untuk penyakit dalam, bedah, kebidanan, lansia dan anak. Padahal, posyandu merupakan perpanjangan tangan dari puskesmas untuk memberikan pelayanan kesehatan di komunitas daerah pedesaan. Biasanaya fasilitas posyandu terdiri dari empat meja pelayanan yang terdiri dari pendaftaran, pengkajian, pengobatan dan penyuluhan kesehatan, oleh karena itu dengan tidak adanya posyandu kesehatan jiwa, masyarakat kurang mendapakan informasi pendidikan kesehatan jiwa.

Masalah-masalah yang dihadapi oleh sekelompok pasien pasca sembuh dari rumah sakit jiwa diatas bisa diatasi dengan mendirikan posyandu kesehatan jiwa. Pengadaan tempat dan orang-orang yang terlibat di masyarakat akan melibatkan Rumah sakit jiwa, Puskesmas, dinas kesehatan dan perangkat desa. Kemudian di tempat tersebut diadakan pelatihan-pelatihan khusus untuk kader kesehatan jiwa. Bentuk dan jenis ketrampilan yang dilatihkan pada kader kesehatan jiwa meliputi pengetahuan dan ketrampilan dalam membantu tenaga kesehatan untuk pelayanan kesehatan jiwa di masyarakat. Pasien yang sudah dinyatakan sembuh dari rumah sakit jiwa dan berada di masyarakat bisa berkonsultasi dan mendapatkan terapi keperawatan atau mendapatkan obat sementara sebelum sempat kontrol ke rumah sakit jiwa atau puskesmas sehingga bisa menurunkan kekambuhan.

Pelatihan ketrampilan yang akan diberikan pada kader kesehatan jiwa meliputi pengetahuan tentang penyakit jiwa dan cara melibatkan pasien penyakit jiwa dimasyarakat. Ketrampilan yang akan diberikan pada kader kesehatan jiwa adalah membantu tenaga kesehatan dengan berlatih bagaimana cara berkomunikasi dengan penderita penyakit jiwa ketika datang ke posyandu, cara menanyakan keluhan pada pasien, cara mencatat keluhan pasien dan menjaga kerahasiannya.

Melalui program transfer ilmu dan teknologi berbasis masyarakat diharapkan kelompok pasien pasca sembuh dari gangguan jiwa mempunyai hubungan atau bersosialisasi dengan masyarakat sekitar, bisa terlibat dalam kegiatan kemasyarakatan sehinnga kualitas hidup pasien meningkat dan berakibat pada angka kekambuhan yang rendah.

Pasien pasca sembuh dari gangguan jiwa di kecamatan Nguter apabila dinyatakan sembuh dan pulang, mereka dikurung keluarganya di dalam kamar atau hanya berdiam diri di dalam rumah, masyarakat juga mengisolasi mereka. Hal ini disebabkan karena kurang pengetahuan masyarakat khususnya keluarga yang mempunyai anggota keluarga gangguan jiwa tentang bagaimana cara merawat anggota keluarga mereka setelah pulang dari rumah sakit jiwa.

Selain itu masalah penting lainya adalah tentang pengobatan. Pasien kadang lupa minum obat, hal ini disebabkan karena pemantauan dari tenaga kesehatan dan keluarga yang kurang mencakup dan ketidak seimbangan antara jumlah tenaga kesehatan dan jumlah pasien yang harus dipantau. Lebih jauh lagi apabila penderita kehabisan 
obat, mereka kadang malas untuk kontrol ke rumah sakit mengingat jarak yang jauh dan kadang harus membayar biaya yang mahal untuk sampai kesana dan mendapatkan obat.

Desa Nguter belum mempunyai posyandu jiwa, sedangkan jumlah penderita gangguan jiwanya sangat tinggi. Selanjutnya perlu bekerjasama antara institusi pendidikan keperawatan, Puskesmas dan rumah sakit jiwa setempat serta bagaimana menggerakan masyarakat untuk mendukung diadakanya pos pelayanan terpadu kesehatan jiwa (posyandu keswa).

Berdasaran permasalah mitra diatas berikut ini adalah hasil identifikasi permasalahan yang dihadapi dan harus dipecahkan oleh kelompok target dan masyarakat di Desa Nguter Kecamatan Nguter kabupaten Sukoharjo:

1. Belum memiliki posyandu keswa tempat rehabilitasi pasca sembuh dari rumah sakit untuk pasien gangguan jiwa yang berbasis di masyarakat.

2. Perlu pengorganisasian masyarakat untuk mensupport pelaksanaan kegiatan dan pelatihan tingkat awal.

3. Belum adanya kader untuk pelayanan posyandu keswa.

4. Kurangnya permodalan untuk memulai program posyandu keswa sebagai salah satu tempat rehabilitasi kelompok masyarakat pasca rawat inap yang sudah dinyatakan sembuh dan kembali ke masyarakat.

\section{Gangguan Jiwa}

Masalah yang terus menerus menyebabkan indifidu tertekan dan akan mengalami stress, apabila tidak ditangani akan menjadi psikosa (Nur Hidayat, 2005). Psikosa atau gangguan jiwa berat dibagi menjadi dua yaitu psikosa organik yang disebabkan oleh penyakit badaniah dan psikosa fungsional dimana psikosa ini belum diketahui penyakit badaniah yang berhubungan (Fontaine and Cook 2003).
Psikosa merupakan suatu gangguan jiwa dengan kehilangan rasa kenyataan atau fakta (sense of reality), pada psikosa ini terdapat gangguan perasaan, afek, dan emosi, proses berfikir, psikomotorik dan kemauan. Pasien tidak merasakan bahwa dirinya sakit. Gejala psikiatrik yang muncul dipengaruhi oleh beberapa hal diantaranya adalah mekanisme pertahanan diri, keadaad psikososial, sifat bantuan dari keluarga, teman, tenaga kesehtan, struktur social dan ciri kebudayaanya. (Kaplan dan Saddock,1997).

Jenis dari psikosa fungsional ini terdiri dari skizoprenia, psikosa afektif, psikosa paranoid dan psikosa reaktif. Psikosa reaktif disebabkan oleh stress psikologik tetapi psikosa yang lain belum diketahui penyebabnya. Skizoprenia merupakan bentuk psikosa yang paling banyak dijumpai sejak dulu sampai sekarang tetapi pengetahuan dan sebab patogenesanya sangat kurang. (Maramis, 1998) Skizoprenia artinya jiwa yang terpecah belah yaitu adanya keretakan atau disharmoni antara proses pikir, perasaan dan perbuatan.. Beberapa teoritisi menyimpulkan penyebab psikosa jenis skizoprenia ini diantaranya adalah disorganisasi kepribadian yang timbul karena reaksi maladaptive, kelemahan ego yang menyebabkan superego dikesampingkan dan mengakibatkan id yang berkuasa.(Stuart, Sundeen,1995).

Gejala primer yang muncul pada pasien gangguan jiwa adalah gangguan proses pikiran, gangguan emosi, gangguan kemauan dan otisme (Maramis, 1998). Gejala tersebut terkait dengan teori kognitif yang menyatakan pola pikiran manusia terbentuk melalui proses rangkaian stimulus kognisi dan respon yang saling terkait dan membentuk tingkah laku atau perbuatan. (Oemarjoedi, 2003) . Proses kognisi pada pasien skizoprenia ini terganggu. Gejala 
kognitif yang terganggua bisa meliputi pemahaman pasien, cara membuat kesimpulan, pemikiran terpolarisasi dansebagainya.

Keadaan jiwa seseorang berarti tingkat dan fungsi jiwa yang mengandung aspek intelegensi, afek, emosi, sikap, minat kepribadian dan psikomotor. (Maramis, 1998). Seseorang yang didiagnosa gangguan jiwa harus diperiksa berbagai komponen diatas, hasil pemeriksaan jiwa seseorang disebut statua mental. Beberapa hal yang diperiksa terkait status mental pasien meliputi afek, emosi, cara berbicara, proses pikir, kesadaran, psikomotor, persepsi, fungsi kognitif, orientasi. Selain pemeriksaan status mental pasien gangguan jiwa juga dikaji criteria psikososialnya (Maramis,1998, Fortinash, Worret, 1999).

Pemeriksaan status mental meliputi : 1). Penampilan pasien yang terdiri dari bagaimana pasien berpakain, kebersihan diri, berdandan dan ekspresi wajah; 2). Perilaku dan aktivitas dikaji apakah pasien hipoaktifitas atau hiperaktifitas, rigit (kaku), rilek, santai, koordinasi motorik, facial grimacing, mannerism,passive, combative; 3).Sikap pasien diperiksa bagaimana interaksi dengan orang lain, kooperatif, resistive, bersahabat; 4). Pembicaraan dikaji bagaimana isi pembicaraan, keras atau lembutnya pasien berbicara, artikulasi, monoton, repetisi, spontan, circumtiality, tangensial, confabulasi, strereotipy, kecepatan; 5). Perasaan (Mood dan affect), mood terdiri dari sedih, takut, marah, cemas, ambivalent, senang, sedangkan afek terdiri dari tumpul, datar, labil, eforia, bizarre; 6). Persepsi terdiri dari pemeriksaan halusinasi, ilusi, depersonalosasi, derealisasi dan distorsi; 7). Isi pikir dikaji mengenai kelogisanya, assosiasi, fligt of idea, autistic, bloking, delusi, abstrak atau kongkrit; 8). Kognisi diperiksa level kebingungan, orientasi, atensi, memori, konsentrasi, kemampuan menyerap proses informasi, dan intelegensinya dan yang terakhirdiperiksa yaitu kemampuan membuat keputusan, keinginan bunuh diri dan insight. (Stuart dan Sundeen,1995, Fortinash, 1999, Stuart dan Laraia, 2001, Fontaine dan Cook, 2003).

Usaha untuk mencegah penyakit adalah dengan mengelola stressor yang datang, pengelolaan tersebut berhubungan dengan bagaimana individu memelihara kesehatannya. Pemeliharaan kesehatan merupakan fungsi otak utama, bagian tengah otah ketika ada stressor akan menstimulasi proses biokimia otak, respon relaksasi adalah usaha tubuh untuk mengembalikan dalam keadaan seimbang

\section{Pos Pelayanan Terpadu}

Menurut Depkes (2006) posyandu adalah pos pelayanan terpadu untuk masyarakat di suatu wilayah tertentu yang sudah disepakati, yang digerakkan oleh masyarakat dimana mereka bisa mendapatkan pelayanan kesehatan. Tujuan pembentukan posyandu antara lain, 1) Meningkatkan jangkauan pelayanan kesehatan di masyarakat, sehingga terbentuk pelayanan kesehatan yang sesuai dengan kebutuhan masyarakat. 2) Mendekatkan pelayanan dan meningkatkan peran serta masyarakat dan swasta dalam pelayanan kesehatan disamping meningkatkan komunikasi antara masyarakat.

Penyelenggaraan posyandu dalam pelaksanaan kegiatan dilakukan oleh anggota masyarakat yang telah dilatih menjadi kader kesehatan dibawah bimbingan puskesmas. Dan pengelola atau pengurus berasal dari kader PKK, 
tokoh masyarakat formal maupun non formal. (Depkes, 2006)

Departemen kesehatan mengharapkan masyarakat dapat bersama-sama mewujudkan kesehatan dengan cara berperan aktif dalam kegiatan posyandu seperti penderita gangguan jiwa terlibat kegiatan penyuluhan, olah raga secara teratur sesuai kemampuan, menjalani pemerikasaan kesehatan secara berkala, menjalani pengobatan dan terapi rehabilitasi, serta meningkatan upaya kemandirian dan pemenuhan kebutuhan pribadi. Kader yang dilibatkan dalam kegiatan posyandu khususnya posyandu kesehatan jiwa telah dibekali cara berkomunikasi dengan penderita penyakit jiwa ketika datang ke posyandu, cara menanyakan keluhan pada pasien, cara mencatat keluhan pasien dan menjaga kerahasiannya.

Jenis pelayanan kesehatan yang dapat diberikan kepada di posyandu berupa pengkajian penderita gangguan jiwa, pemeriksaan aktivitas kegiatan seharihari, pemeriksaan status mental, pengukuran tekanan darah, memberikan pengetahuan tentang gangguan jiwa, memberikan terapi pengobatan dan penatalaksaan mekanisme koping yang adaptif bagi penderita gangguan jiwa serta keluarga. Pelaksanaan rujukan ke puskesmas bila ditemukan kelainan dimana tidak dapat diberikan di lingkup posyandu tingkat dasar.

Kegiatan pengabdian pada masyarakat ini bertujuan:

1. Membentuk posyandu keswa dengan home base masyarakat sebagai tempat pelayanan pertama dan rehabilitasi penderita gangguan jiwa yang sudah dinyatakan sembuh di masyarakat.

2. Membantu menciptakan pelayanan kesehatan primer yang merupakan perpanjangan tangan dari rumah sakit dan puskesmas.

3. Meningkatkan pengetahuan masyarakat, kemudahan pengobatan pasien gangguan jiwa dan sosialisai pasien gangguan jiwa dengan masyarakat sekitar yang difasilitasi oleh posyandu keswa.

Adapun manfaatnya adalah:

1. Tersedianya fasilitas pelayanan kesehatan pertama bagi penderita gangguan jiwa di masyarakat.

2. Membantu/memfasilitasi pelayanan kesehatan jiwa bagi penderita gangguan jiwa.

3. Meningkatnya pemahaman masyarakat tentang ganguan jiwa.

4. Menurunkan angka kekambuhan penderita gangguan jiwa di masyarakat.

5. Mencegah bertambahnya angka penderita gangguan jiwa di masyarakat desa Nguter.

6. Meningkatnya produktifitas penderita gangguan jiwa di masyarakat.

\section{METODE PELAKSANAAN}

Melalui kegiatan PAKOM ini dicarikan solusi bagi permasalahanpermasalahan yang telah dirumuskan di atas. Pendekatan yang ditawarkan bagi realisasi program PAKOM ini adalah model pemberdayaan dengan langkah-langkah yang telah dilakukan sebagai berikut tahap persiapan, tahap perencanaan program kegiatan, tahap pelaksanaan kegiatan, tahap evaluasi kegiatan, serta tahap terminasi.

Pelaksanaan program PAKOM ini dilaksanakan sebagai upaya pemberdayaan kelompok pasien pasca sembuh dari gangguan jiwa dalam bidang keperawatan jiwa komunitas melalui pengadaan posyandu keswa yang melibatkan dukungan dari masyarakat setempat. Metode pelaksanaan program yang akan dilakukan adalah : (1) pembentukan home base posyandu keswa di masyarakat. (2) Pelatihan pelayanan 
posyandu keswa yang terdiri dari 5 meja. Semua metode ini merupakan satu kesatuan dari program PAKOM ini.

\section{Tahap persiapan}

Tahap persiapan dilakukan dengan memulai koordinasi dengan key person, perangkat kecamatan dan perangkat desa Nguter. Koordinasi akan menjelaskan pentingnya keterlibatan dan dukungan masyarakat dalam ikut memelihara lingkungan dengan berperan serta mencegah kekambuhan pasien yang telah sembuh dari sakit jiwa yang pulang dari rumah sakit.

Pada tahap persiapan ini menjelaskan kepada perangkat desa bentuk kegiatan yang akan dilakukan yaitu membuat posyandu keswa sebagai tempat pelayanan primer untuk pasien yang telah dinyatakan sembuh dari rumah sakit jiwa yang bertempat di masyarakat. Selanjutnya tim pengabdian juga akan menjelaskan apa saja kegiatan yang akan dilakukan, struktur organisasi dan tugas dari tim pengabdian dan tugas dan masyarakat.

Setelah dicapai kesepakatan, masih pada tahap persiapan, tim pengabdian bersama key person akan mengidentifikasi kelompok masayarakat target (kelompok pasien gangguanU jiwa, mendata, mendaftar, untuk didikutsrtakan dalam kegiatan posyandu keswa.

\section{Tahap pelaksanaan kegiatan}

Pada tahap pelaksanaan kegiatan tim pengabdian menyusun rencana kegiatan yang akan diaplikasikan pada 2 mitra. Rencana kegiatan meliputi kapan kegiatan akan dimulai dan berakhir (waktu), apa bentuk kegiatannya, siapa yang mengkoordinir, berapa lama, medianya apa, methodenya apa, tempatnya dimana, siapa pembicaranya, siapa yang diundang. Untuk lebih jelasnya bias dilihat pada table dibawah ini:

Tabel.1.

Pelaksanaan kegiatan PAKOM posyandu keswa

\begin{tabular}{|c|c|c|c|}
\hline Kegiatan & $\begin{array}{c}\text { Pembicara } \\
\text { /koordinator }\end{array}$ & $\begin{array}{l}\text { Media dan } \\
\text { metode }\end{array}$ & Tempat \\
\hline Pertemuan warga & Tim PAKOM & Ceramah diskusi & $\begin{array}{l}\text { Balai } \\
\text { Kelurahan }\end{array}$ \\
\hline $\begin{array}{l}\text { Koordinasi pembentukan } \\
\text { posyandu keswa }\end{array}$ & $\begin{array}{l}\text { Tim PAKOM } \\
\text { Puskesmas, jurusan } \\
\text { keperawatan, kepala } \\
\text { desa }\end{array}$ & $\begin{array}{l}\text { Ceramah } \\
\text { Diskusi } \\
\text { Lefleat } \\
\text { Lembar balik } \\
\text { LCD }\end{array}$ & $\begin{array}{l}\text { Balai } \\
\text { Kelurahan }\end{array}$ \\
\hline $\begin{array}{l}\text { Koordinasi pengarahan uraian } \\
\text { tugas antara tim pengabdian dan } \\
\text { masyarakat }\end{array}$ & $\begin{array}{l}\text { Tim PAKOM } \\
\text { Pengurus desa }\end{array}$ & $\begin{array}{l}\text { Ceramah } \\
\text { Diskusi }\end{array}$ & $\begin{array}{l}\text { Balai } \\
\text { Kelurahan }\end{array}$ \\
\hline $\begin{array}{l}\text { Pelatihan pengurus desa tentang } \\
\text { pengorganisasian tempat } \\
\text { posyandu }\end{array}$ & Abi Muhlisin & $\begin{array}{l}\text { Ceramah } \\
\text { Diskusi } \\
\text { Lefleat } \\
\text { Lembar balik } \\
\text { LCD }\end{array}$ & $\begin{array}{l}\text { Balai } \\
\text { kelurahan }\end{array}$ \\
\hline $\begin{array}{l}\text { Pelatihan uraian tugas kader } \\
\text { keswa }\end{array}$ & Arum Pratiwi & $\begin{array}{l}\text { Ceramah } \\
\text { Praktik } \\
\text { pendampingan }\end{array}$ & $\begin{array}{l}\text { Balai } \\
\text { kelurahan }\end{array}$ \\
\hline $\begin{array}{l}\text { Pelatihan penempatan } 4 \text { meja } \\
\text { posyandu keswa }\end{array}$ & Agus sudaryanto & $\begin{array}{l}\text { Ceramah } \\
\text { Praktik } \\
\text { pendampingan }\end{array}$ & $\begin{array}{l}\text { Balai } \\
\text { kelurahan }\end{array}$ \\
\hline $\begin{array}{l}\text { Koordinasi keberlanjutan } \\
\text { posyandu keswa }\end{array}$ & Sahuri teguh & $\begin{array}{l}\text { Ceramah } \\
\text { Praktik } \\
\text { pendampingan }\end{array}$ & $\begin{array}{l}\text { Balai } \\
\text { kelurahan }\end{array}$ \\
\hline
\end{tabular}




\begin{tabular}{l|l|l|l|}
\hline $\begin{array}{l}\text { Mengarahkan dan memandirikan } \\
\text { masyarakat }\end{array}$ & Tim PAKOM & $\begin{array}{l}\text { Observasi } \\
\text { Pendampingan }\end{array}$ & $\begin{array}{l}\text { Balai } \\
\text { kelurahan }\end{array}$ \\
\hline Menilai keberhasilan kegiatan & Tim PAKOM & $\begin{array}{l}\text { Observasi } \\
\text { Pendampingan }\end{array}$ & $\begin{array}{l}\text { Balai } \\
\text { kelurahan }\end{array}$ \\
\hline
\end{tabular}

\section{Uraian Kegiatan}

Pengajaran yang telah dilakukan pada kader meliputi cara penerimaan, pencataan dan pemantauan secara administrasi pasien di posyandu, pelatihan penyuluhan kesehatan di meja 4 yang meliputi pelatihan cara mengingatkan minum obat pada pasien, pelatihan penyuluhan pasien dalam aktifitas sehari-hari.

Fasilitas pelatihan di dibuat modul psiko-edukasi kader posyandu keswa. Modul ini dibagikan dan dipelajari selama proses pelatihan. Evaluasi dilakukan melalui pretes dan postes menggunakan soal pilihan ganda.

\section{HASIL DAN PEMBAHASAN}

\section{Tahap Persiapan}

Persiapan pelaksanaan kegiatan meliputi pertemuan warga, koordinasi pembentukan posyandu keswa, koordinasi pengarahan uraian tugas antara tim pengabdian dan masyarakat. Pada pelaksanaan tahap pertama yaitu pertemuan warga dilaksanakan dirumah Ibu Poniyem kelurahan nguter pada tanggal 23 Mei 2014 pada pukul 19.30- 22.00 WIB, dalam pertemuan tersebut di hadiri oleh tokoh masyarakat, pemuda dan pejabat pemerintahan desa nguter serta tim PAKOM.

Dalam kesempatan tersebut di bahas tentang rencana pelaksanaan posyandu kesehatan jiwa yang berada di nguter meliputi penjelasan urian kegiatan, penjelasan pengorganisasian posyandu , pembentukan kader, pelatihan kader. Metode penyampaian informasi/ koordinasi dengan masyarakat tentang posyandu kesehatan jiwa menggunakan metode ceramah, diskusi, LCD dan tanya jawab. Dari pertemuan tersebut telah disepakati pelatihan kepada kader di laksanakan pada hari sabtu tanggal 31 mei 2014.

\section{Tahap Pelaksanaan}

Setelah dilaksanakan pertemuan pertama pada tanggal 23 Mei 2014 dilanjutkan pertemuan dengan kader untuk memberikan pemahaman tentang pengorganisasian kader serta pelatihan tentang pelaksanaan posyandu kesehatan jiwa di komunitas. Pelaksanan kegiatan ini dilaksanakan di rumah ibu poniyem dan dilaksanakan pada tanggal 31 Mei pada pukul 13.00 WIB yang dihadiri oleh tim PAKOM, pegawai pemerintahan dan kader yang telah di tunjuk. Dalam kegiatan tersebut juga disampaikan pentingnya posyandu kesehatan jiwa yang salah satunya berfungsi untuk memberikan fasilitas pelayanan kesehatan pertama bagi penderita gangguan jiwa di masyarakat, serta diharapkan pemahaman kader/ masyarakat tentang ganguan jiwa dapat meningkat melalui kegiatan posyandu kesehatan jiwa.

Pelatihan penempatan yang berfokus pada meja ke 4 tentang mengingatkan minum obat serta kegiatan sehari-hari bagi penderita gangguan jiwa ini di sampaikan oleh tim Pakom melalui metode ceramah, diskusi dan praktik/ demontrasi. Dalam kegiatan di tahap pelaksanaan ini didapatkan hasil bahwa kader memahami tentang uraian tugas dan pelaksanaan pelayanan kesehatan jiwa di masyarakat. Di akhir kegiatan dilaksanakan praktek/ demontrasi tentang alur pendaftaran dari klien masuk sampai klien keluar serta dilanjutkan diskusi yang membahas tentang komunikasi therapeutik kepada penderita gangguan jiwa, obat yang dikonsumsi oleh penderita gangguan jiwa serta kegiatankegiatan yang dapat dilakukan oleh penderita gangguan jiwa. 


\section{SIMPULAN DAN SARAN}

\section{Simpulan}

Pasien pasca sembuh dari gangguan jiwa yang masih bergantung menjadi beban ketergantungan dalam keluarg, pengetahuan masyarakat yang kurang tentang gangguan jiwa menyebabkan penderita gangguan jiwa banyak kambuh karena diisolir dianggap tidak berguna dan di asingkan, pelayanan posyandu yang jauh dari lingkungan tempat tinggal juga menjadi salah satu pemicu kambuhnya penderita gangguan jiwa karena tidak optimalnya pelayanan kesehatan dasar di masyarkat. posyandu keswa dengan home base masyarakat sebagai tempat pelayanan pertama dan rehabilitasi penderita gangguan jiwa, dalam kegiatan posyandu kesehatan jiwa ini membantu menciptakan pelayanan kesehatan primer yang merupakan perpanjangan tangan dari rumah sakit dan puskesmas.

\section{Saran}

Dinas Kesehatan Kabupaten Sukoharjo sebaiknya mulai memperhatikan kader yang telah ada di masyarakat,baik dari kesejahteraan kader maupun pengakuan dari dinas kesehatan baik kader kesehatan jiwa maupun kader yang lain. Tanpa bantuan dan peran kader, pelayanan kesehatan dasar di masyakarat tidak dapat berjalan, tenaga kesehatan baik bidan, perawat maupun dokter yang ada dimasyarakat tidak dapat berbuat sesuatu tanpa bantuan kader. Kader kesehatan jiwa yang sudah terbentuk di nguter harapannya dapat di tanggapi serius oleh dinas kesehatan kabupaten sukoharjo sehingga dapat di tindaklanjuti menjadi desa percontohan dalam mengelola dan merawat penderita gangguan jiwa di masyarakat.

\section{PERSANTUNAN}

Kegiatan pengelolaan posyandu kesehatan jiwa ini dapat terlaksana karena dukungan dari berbagai pihak, untuk itu kami mengucapkan terimakasih kepada :

1. Kepala Lembaga Pengabdian Masyarakat, yang telah memfasilitasi kegiatan pengabdian masyarakat ini.

2. Kepala desa Nguter Kabupaten sukoharjo yang telah mengijinkan pelaksanaan kegiatan ini.

3. Kader dan masyarakat Desa Nguter telah berperan aktif dalam pelaksaan mulai dari awal kegiatan sampai selesai.

\section{DAFTAR PUSTAKA}

Departemen Kesehatan RI. 2006. Pedoman Pelatihan Kader Kelompok Usia Lanjut Bagi Petugas Kesehatan. Jakarta : Direktorat Kesehatan Keluarga

Fontaine and Cook . 2003. Esential of Mental Health Nursing, California, Addson- Wessley Publising Company.

Ibrahim, A. 2004. Antioksidan dan Perannya Mengatasi Penuaan (Sistem pertahanan (Numeria).WWW. Msikes.com.

Keefe, R.S.E., et al. 2006. The Schizophrenia Cogmition Rating Scale: An, Interview Based Assesment and its Relationship to cognition, Real-Word Functioning, and Functional Capacity.

Kaplan, H.I, Saddock, B.J, Grebb. J.K.1997. Ilmu Pengetahuan Perilaku Psikiatri Klinis: Sinopsis Psikiatri, terjemahan, Jakarta, Binarupa aksara.

Nur Hidayat, Y., Trim B. 2005. Rahasia sistem Imun dan Kiat menghadapi penyakit, Bandung. Kakibuku. 
Pratiwi, A. 2006. Pengaruh Teknik Relaksasi terhadap perbaikan status mental pasien gangguan jiwa, Penelitian reguler UMS, tidak dipublikasikan

2007. Dampak pemberian vitamin $C$ terhadap nilai limposit dan hubungannya dengan kemampuan kognitif pasien gangguan jiwa, Penelitian reguler UMS, tidak dipublikasikan

Priestley, J. 2005. Immune system Disorder Nutritional Therapy. Omni Medical Center, Avenue, http//www. Helthoes. Com.

Shelton RC, Williamson DJ, Corya SA, et al, Olanzapine plus fluoxetine reduce depressive symptoms faster than either drug alone in people with treatment resistant depression, Journal of Clin Psychiatry 2005;66:1289-97. 